\title{
Epiphysial dysplasia: a constant finding in the XXXXY syndrome
}

\author{
RINA SCHMIDT ${ }^{1}$, MAX PAJEWSKI, AND MALKA ROSENBLATT \\ From the Cytogenetic Laboratory and Department of Roentgenology, Asaf-Harofe Government Hospital, and \\ Tel-Aviv University Medical School, Zrifin, Israel
}

SUMMARY Two patients with the XXXXY syndrome are presented. Both boys are mentally retarded ${ }_{\overrightarrow{0}}^{*}$ with short stature, muscular hypotonia, and hypogonadism. A constant feature of this syndrome is $a_{A}$ varying degree of epiphysial dysplasia probably secondary to hypotonia and growth deceleration.

The XXXXY syndrome was first reported by Fraccaro et al. in 1960 and 1962 and later defined by Zaleski et al. in 1966. The important features are mental retardation, typical facial expression, hypogonadism, and skeletal deformities. Houston (1967) summarised the radiological findings of 28 cases obtained from 23 different countries throughout the world. Bone deformities were found in the elbows, wrists and hands, pelvis and hips, knees, ankles and feet, skull, spine, and sternum. Typical radiological features are radioulnar synostosis and dislocation, 'pseudoepiphyses', curved 5th finger and short 5th middle phalanx, coxa valga, sclerotic cranial sutures, thick cranial vaults, and thick sternum.

About 100 cases have been reported so far (Terheggen et al., 1973; Karsh et al., 1975). In some patients various forms of mosaicism, 47,XY/ 48, XXXY/49, XXXXY; $48, \mathrm{XXXX/49,XXXXY;}$ 48, XXXY/49,XXXXY; and 48, XXXX/49,XXXXY/ 49,XXXXi-(Yq) were found (Kardon et al., 1971; Kaluzewski et al., 1977).

The purpose of this report is to describe 2 additional cases of the 49,XXXXY syndrome and to indicate that, though skeletal abnormalities vary from case to case, features consistent with epiphysial dysplasia of the long bones are consistently present.

\section{Case reports}

CASE 1

A male was born 14 April 1966 with asphyxia livida, Apgar 1. Birthweight was $2.8 \mathrm{~kg}$. The pregnancy was

1 Present address: Genetic Counseling Program, Rose F. Kennedy Center for Research in Mental Retardation and Human Development and the Department of Pediatrics, Albert Einstein College of Medicine, Bronx, New York 10461, USA.

Received for publication 17 October 1977 complicated by heavy vaginal bleeding in the fourth $\stackrel{5}{\text { ? }}$ month.

The parents were unrelated of Persian-Jewish origins The father was 29 years old, the mother 24 years old $\frac{c}{?}$ at his birth. They had two older sons, the firstborn $\vec{c}$ having died at the age of 1 month from ileus of unknown cause. An older brother, aged 14, had unilateral cryptorchidism.

At birth the child had a round facies with low hair line, hypertelorism, and a short nose. The testes ando penis were small. A systolic murmur was heard on theő left side of the sternum. Electrocardiogram and chest $\stackrel{\circ}{\circ}$ $x$-ray film showed enlargement of the left ventricle. $\overrightarrow{\overrightarrow{0}}$ The child was treated with oxygen and digitalis. Sub-3 sequently, his condition improved and the treatment? was stopped. Psychomotor development was slow. HeO sat up at 2 years, walked at 3 , and spoke a few words at $3 \frac{1}{2}$ years. At 14 months a developmental assess ment disclosed a motor and social development of 6 to 8 months. Another assessment at 21 months indicated a developmental age of 10 months. At $5 \frac{1}{2}$ he waso̊ retested by the same psychologist and scored $a ß$ developmental age of 2 years and 8 months or an IQO of 49 (revised Terman-Merrill).

Physical examination at 6 years showed a shorto retarded boy with round facies, short neck, clinodactyly, pes valgus, and genu valgum (Fig. 1). His. penis was very short and the descended testes were 0 small. Head circumference was $48 \mathrm{~cm}$ (average for $18 \mathrm{~N}$ months), weight $21.5 \mathrm{~kg}$, height $105 \mathrm{~cm}$ (average foro $4 \frac{1}{2}$ years).

Routine laboratory tests were within normal limits. Cytogenetic investigations showed a karyotype of? 49,XXXXY. Buccal smears showed 3 sex chromatino bodies. Autoradiography and Q-banding also con-0 firmed the presence of $4 \mathrm{Xs}$ in all the cells. Testicular员 282 


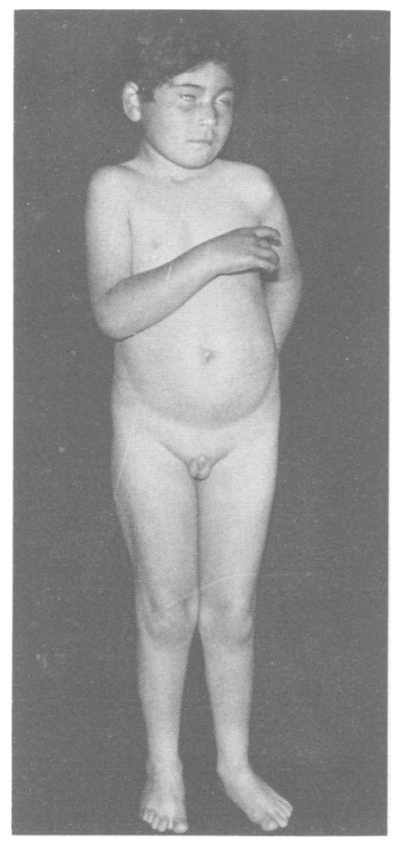

Fig. 1 Case 1 at the age of 6 years. A retarded male, small for his age with peculiar facial expression and hypogonadism. biopsy, performed at age 6 years, disclosed a complete absence of Leydig cells. Cytogenetic studies of the parents and the brother were normal. Dermatoglyphic findings are summarised in the Table.

The radiological abnormalities were confined to the epiphyses. Radiography of the hands (Fig. 2) showed pseudoepiphyses of the first, second, and fifth metacarpals, curving of the fifth finger, and secondary shortening and deformity of the middle phalanx, with pointed middle phalanges of the other fingers. The left distal radial epiphysis, proximal first metacarpal epiphysis, and the ossification centre of the lunatum minor were smaller than their metaphysial right counterparts. A marginal defect with punctate calcifications was observed in the left radius. Radiography of the pelvis (Fig. 3a) showed bilateral coxa valga. All the epiphyses of the lower extremities were affected (Fig. 3b) showing different degrees of hypoplasia, deformity, and irregular mineralisation. The proximal femoral epiphyses were triangular and small, the distal epiphyses appeared cone shaped and slightly mottled, and some irregularities were seen on their lateral edges. The right proximal fibular epiphysis was absent. The distal tibial epiphyses were thin, oblique, and triangular plates, covering only partially the tibial distal ends.

\section{CASE 2}

This boy was born in India to a 26-year-old mother and 40 -year-old father who were not related. $\mathrm{He}$ is the

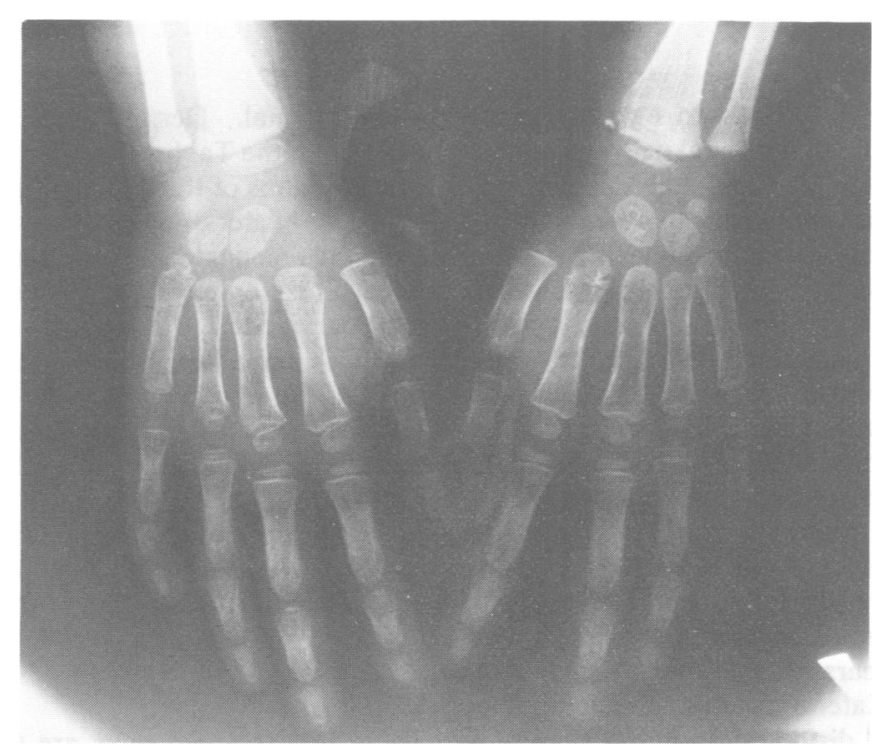

Fig. 2 Case 1, x-ray films of the hands, showing pseudoepiphyses of the first, second, and fift metacarpals, curving of the fifth finger, and secondary shortening and deformity of the fift thiddle phalanx. The other fingers have pointed middle phalanges. Differences in involvement of both sides are noted. The distal radial epiphysis and the ossification centre of the lunatum minor are smaller on the left side. In the left radius, a marginal defect with punctate calcifications can be seen. 


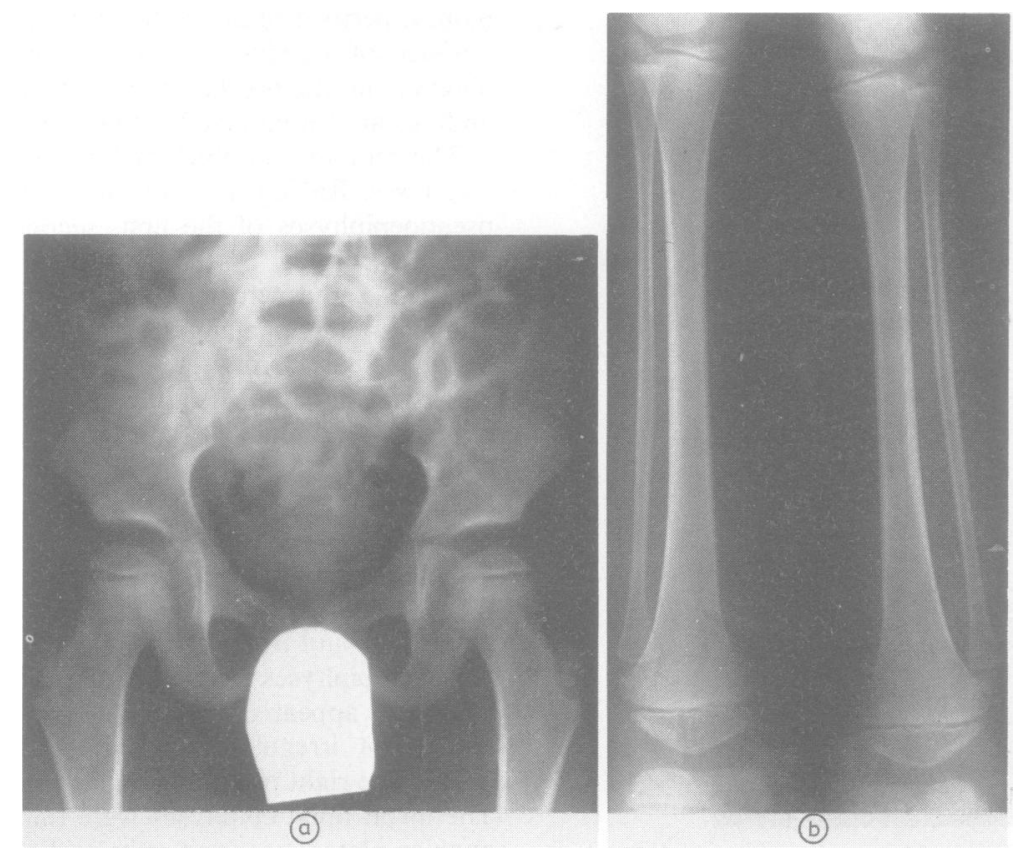

Fig. 3 Case 1, x-ray films of the pelvis (a) and lower extremities (b). There is bilateral coxa valga. All the epiphyses of the lower extremities show different degrees of hypoplasia, deformity, and irregular mineralisation. The proximal femoral epiphyses are triangular and small. The distal epiphyses appear cone-shaped and slightly mottled with some irregularities on their lateral edges. The right proximal fibular epiphysis is absent. The distal tibial epiphyses appear as thin, oblique, and triangular plates, covering only partially the tibial distal ends. The left tibial epiphysis seems to be somewhat smaller than the right.

fifth of seven sibs, ranging from 20 to 1 years. Before his birth the mother had had 4 normal deliveries and 2 miscarriages. There were 2 additional miscarriages after the birth of the last child. The parents and the other children were normal and in good health.

Pregnancy and delivery were apparently normal. Development was retarded. He walked at $1 \frac{1}{2}$ years, and never spoke more than a few words. At the age of about 2 years he presumably had poliomyelitis and was left with partial paralysis of the left leg.

Physical examination at 11 years of age showed a profoundly retarded, slender boy with a peculiar facial expression. His height was $139 \mathrm{~cm}$ (25th centile), weight $23 \mathrm{~kg}$ (average for $6 \frac{1}{2}$ years). Head circumference was $49 \mathrm{~cm}$ (average for 2 years). There was distinct hypertelorism, epicanthi and mongoloid slants of the eyes, low set ears with a preauricular tag, webbing of the neck, bilateral clinodactyly, limitations of joint movements and disfiguration of the elbows, a short penis, and small testes (Fig. 4).

Cytogenetic investigations showed a karyotype of 49, XXXXY. In buccal smears, 3 Barr bodies were seen. The karyotypes of his parents and one sister were normal. Dermatoglyphic findings are sum $\frac{3}{2}$ marised in the Table.

$X$-ray films of the upper extremities (Fig. $5 \mathrm{a}$ and $5 \mathrm{~b}$ ) showed bilateral radioulnar synostosis and dis location, elongated distal ulnae, hypoplastic righto distal ulnar epiphysis in comparison with its normaB left counterpart, pseudoepiphyses of the first, second and fifth metacarpals, and curved fifth finger. $X$-ray films of the lower extremities (Fig 6a and 6b) showe bilateral coxa valga. The distal tibial epiphyses were wedge-shaped because of deficiency of their laterat parts.

$X$-ray pictures of the skull (Fig. 7) showed uni $N$ formly thickened calvaria, digital markings, and absence of pneumatisation of the paranasal sinuses.

\section{Discussion}

These two retarded boys are typical examples of the XXXXY syndrome. It is well known that the diagnosis of this chromosomal aberration can be made at birth on clinical grounds (Hayek et al., 1971) $\overrightarrow{\mathbb{D}}$ Indeed, case 1 was noted to be 'peculiar' at birth, with 


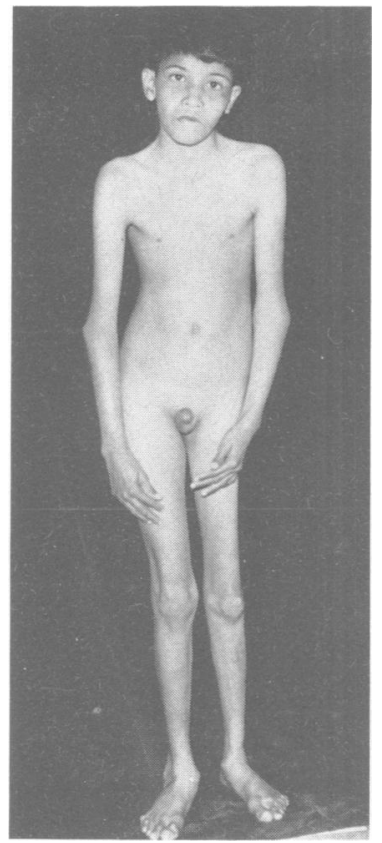

Fig. 4 Case 2 at the age of 11 years. A profoundly retarded slender boy with microcephaly, hypertelorism, mongoloid slants, low set ears, webbing of the neck, bilateral dislocations of the elbows, and hypogonadism.

the typical 'round face', hypogonadism, and epiphysial involvement. Case 2 had dislocation of the elbows and many other bone deformities in addition to epiphysial dysplasia. Both children were mentally retarded, a feature which frequently accompanies a multiple $\mathrm{X}$ syndrome.

Case 1, though somewhat retarded at 15 months, decelerated in his mental functions, a finding that has also been noted by Shapiro et al. $(1970,1971)$ in their XXXXY patient.
The dermatoglyphic patterns of both patients and their parents (Table) were essentially normal. No arches were observed on any of their fingers. Moreover, the total ridge counts (TRC) in both patients were higher than those of one of their parents. This finding is in accordance with Zaleski et al. (1966). However, Penrose (1967) stated that subjects with multiple $\mathbf{X}$ chromosome patterns have a tendency towards lower TRCs, and Sergovich et al. (1971) had observed simple arch patterns on all the fingers of their patient with the XXXXX syndrome.

The osseous deformities in individuals affected with the XXXXY chromosomal aberration are numerous and at first sight apparently lacking any common denominator. We share the opinion of Houston (1967) that some of the bone changes are the result of an entirely non-specific osseous response which is secondary to the altered mechanical stress acting on the bones.

In these patients muscular hypotonia, though of varying severity, is almost always present. The hypotonia is probably the underlying cause of square vertebrae, scoliosis, coxa valga, and slenderness of the long bones and iliac wings. Similarly, because of impaired brain growth, the cranial vaults are thickened, the digital markings lacking or diminished, and the cranial sutures prematurely sclerotic. It is evident, therefore, that the presence and severity of these secondary bone changes are directly related to the degree of motor impairment and the deceleration of brain growth.

We believe that many of the well-known osseous deformities such as sternal undersegmentation and thickening, radioulnar synostosis and dislocation, clinodactyly, pseudoepiphyses, etc. are inherent to a basic cellular pathology resulting from the excess of inactive chromosomal mass, which leads to slowed synthesis of DNA in various tissues (Mittwoch, 1972). Impaired growth, differentiation, and maturation may result.

Table Dermatoglyphs

\begin{tabular}{|c|c|c|c|c|c|c|c|c|c|c|c|c|c|c|}
\hline & & \multicolumn{8}{|c|}{ Fingers } & \multicolumn{5}{|c|}{ Palms } \\
\hline & & I & II & III & IV & $\mathbf{V}$ & TRC & $\begin{array}{l}a b \\
(\mathrm{~mm})\end{array}$ & $\begin{array}{l}a b \\
\text { ridges }\end{array}$ & $a t d^{\circ}$ & Interd & gital & Hypothenar & Thenar \\
\hline Case 1 & R & $\begin{array}{l}W^{c} \\
W^{d}\end{array}$ & $\begin{array}{l}W^{s} \\
W^{s}\end{array}$ & $\begin{array}{l}W^{s} \\
W^{s}\end{array}$ & $\begin{array}{l}W^{c} \\
W^{s}\end{array}$ & $L^{u}$ & 185 & 16 & 70 & 87 & $\overline{I V}_{-d}$ & & $\mathbf{L}$ & - \\
\hline Mother & $\begin{array}{l}\mathrm{L} \\
\mathbf{L}\end{array}$ & $\begin{array}{l}W^{s} \\
W^{s}\end{array}$ & $\begin{array}{l}W^{c} \\
W^{s}\end{array}$ & $\begin{array}{l}W^{c} \\
W^{s}\end{array}$ & $\begin{array}{l}W^{c} \\
W^{s}\end{array}$ & $\begin{array}{l}L^{u} \\
L^{u}\end{array}$ & 232 & $\begin{array}{l}20 \\
20 \\
20\end{array}$ & 70 & 84 & $\begin{array}{l}\text { IV-d } \\
\text { III-L } \\
\text { IIIOL }\end{array}$ & $\begin{array}{l}\text { III-L } \\
\text { IV-W } \\
\text { IV-d }\end{array}$ & $\bar{L}$ & - \\
\hline Father & $\begin{array}{l}\mathbf{R} \\
\mathbf{L}\end{array}$ & $\begin{array}{l}W^{\mathbf{s}} \\
W^{s}\end{array}$ & $\begin{array}{l}W^{c} \\
W^{c}\end{array}$ & $\begin{array}{l}L^{u} \\
L^{u}\end{array}$ & $\begin{array}{l}\mathbf{W}^{\mathbf{c}} \\
\mathbf{L}^{\mathbf{u}}\end{array}$ & $\begin{array}{l}\mathrm{L}^{\mathbf{u}} \\
\mathrm{L}^{\mathbf{u}}\end{array}$ & 163 & $\begin{array}{l}22 \\
22\end{array}$ & 76 & 79 & $\begin{array}{l}\text { III-L } \\
\text { III-L }\end{array}$ & & - & - \\
\hline Case 2 & $\begin{array}{l}\mathbf{R} \\
\mathbf{L}\end{array}$ & $\begin{array}{l}W^{c} \\
W^{d}\end{array}$ & $\begin{array}{l}\mathbf{L}^{u} \\
\mathbf{L}^{\mathbf{u}}\end{array}$ & $\begin{array}{l}L^{u} \\
W^{s}\end{array}$ & $\begin{array}{l}W^{c} \\
L^{u}\end{array}$ & $\begin{array}{l}W^{c} \\
L^{r}\end{array}$ & 109 & $\begin{array}{l}18 \\
19\end{array}$ & 71 & 79 & $\begin{array}{l}\text { IV-L } \\
\text { IV-L }\end{array}$ & & - & - \\
\hline Mother & $\begin{array}{l}\mathbf{R} \\
\mathbf{L}\end{array}$ & $\begin{array}{l}\text { A } \\
\text { A }\end{array}$ & $\begin{array}{l}\mathbf{L}^{\mathbf{u}} \\
\mathbf{L}^{\mathbf{u}}\end{array}$ & $\begin{array}{l}\mathbf{L}^{\mathbf{u}} \\
\mathbf{L}^{\mathbf{u}}\end{array}$ & $\begin{array}{l}W^{c} \\
W^{c}\end{array}$ & $\begin{array}{l}\mathbf{L}^{\mathbf{u}} \\
\mathbf{L}^{\mathbf{u}}\end{array}$ & 87 & $\begin{array}{l}20 \\
22\end{array}$ & 73 & 66 & $\begin{array}{l}\text { III-L } \\
\text { IV-L }\end{array}$ & & - & - \\
\hline Father & $\begin{array}{l}\mathbf{R} \\
\mathbf{L}\end{array}$ & $\begin{array}{l}W^{s} \\
W^{s}\end{array}$ & $\begin{array}{l}\mathbf{W}^{\mathbf{c}} \\
\mathbf{W}^{\mathbf{s}}\end{array}$ & $\begin{array}{l}\mathbf{W}^{\mathbf{c}} \\
\mathbf{L}^{\mathbf{u}}\end{array}$ & $\begin{array}{l}W^{c} \\
W^{s}\end{array}$ & $\begin{array}{l}\mathbf{L}^{u} \\
\mathbf{L}^{u}\end{array}$ & 219 & $\begin{array}{l}21 \\
23\end{array}$ & 98 & $97 \cdot 5$ & $\begin{array}{l}\text { III-L } \\
\text { III-L }\end{array}$ & & - & - \\
\hline Sister & $\begin{array}{l}\mathbf{R} \\
\mathbf{L}\end{array}$ & $\begin{array}{l}\mathbf{L}^{\mathbf{u}} \\
\mathbf{L}^{\mathbf{u}}\end{array}$ & $\begin{array}{l}\mathbf{L}^{\mathbf{u}} \\
\mathbf{L}^{\mathbf{r}}\end{array}$ & $\begin{array}{l}\mathbf{L}^{\mathbf{u}} \\
\mathbf{W}^{\mathbf{c}}\end{array}$ & $\begin{array}{l}W^{c} \\
W^{c}\end{array}$ & $\begin{array}{l}\mathbf{L}^{\mathbf{u}} \\
\mathbf{L}^{\mathbf{u}}\end{array}$ & 149 & $\begin{array}{l}22 \cdot 5 \\
23\end{array}$ & 84 & 87 & $\begin{array}{l}\text { IV-L } \\
\text { IV-L }\end{array}$ & & - & - \\
\hline
\end{tabular}

A, arch; L. loop: W, whorl; u. ulnar; r, radial; c, concentric; s, spiral; d, double; TRC, total ridge count. 


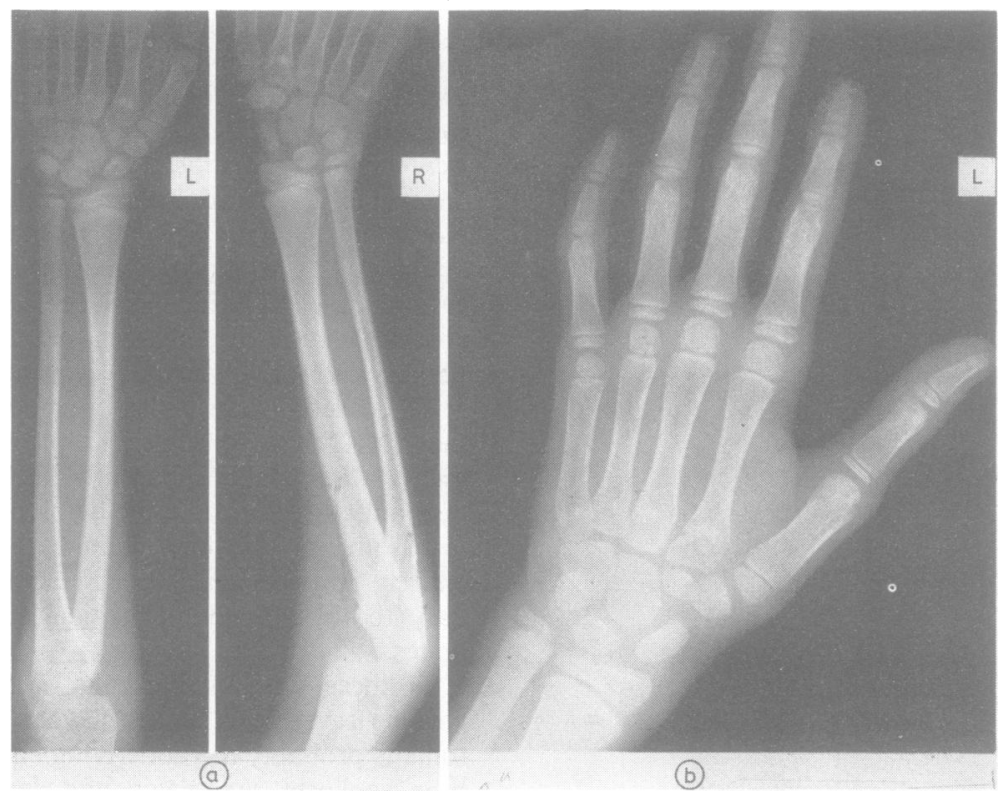

Fig. 5a, 5b Case 2, x-ray films of the upper extremities, showing bilateral radioulnar synostoses and dislocations, elongated distal ulnae, hypoplastic right distal ulna epiphysis, pseudoepiphyses of the first, second, and fifth metacarpals, curved little finger.

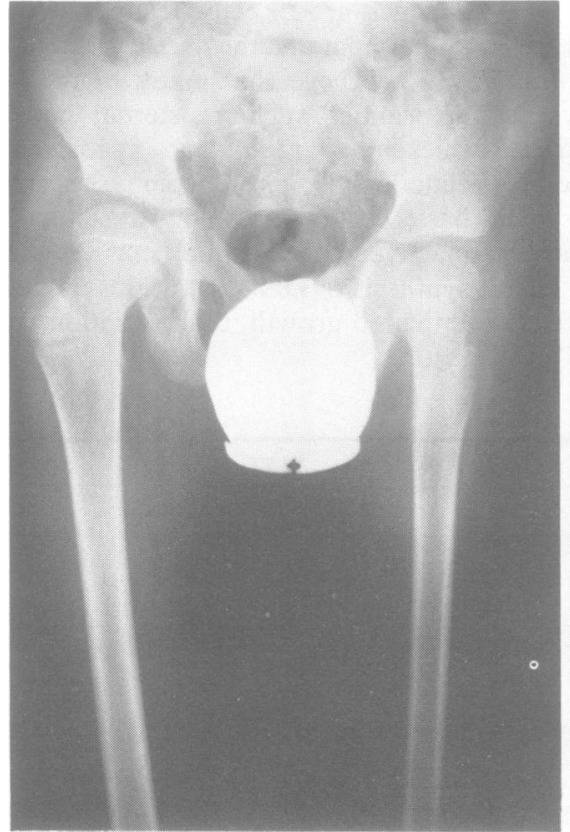

(a)

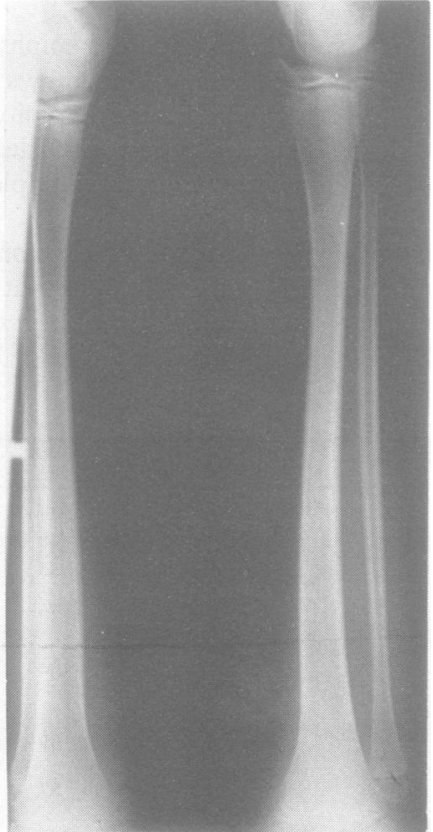

(b)

Fig. $6 \mathrm{a}, 6 \mathrm{~b}$ Case $2, x$-ray films of the pelvis (a) and lower extremities (b) showing bilateral coxa valga. The distal tibial epiphyses are wedge shaped because of deficiency of their lateral parts. 


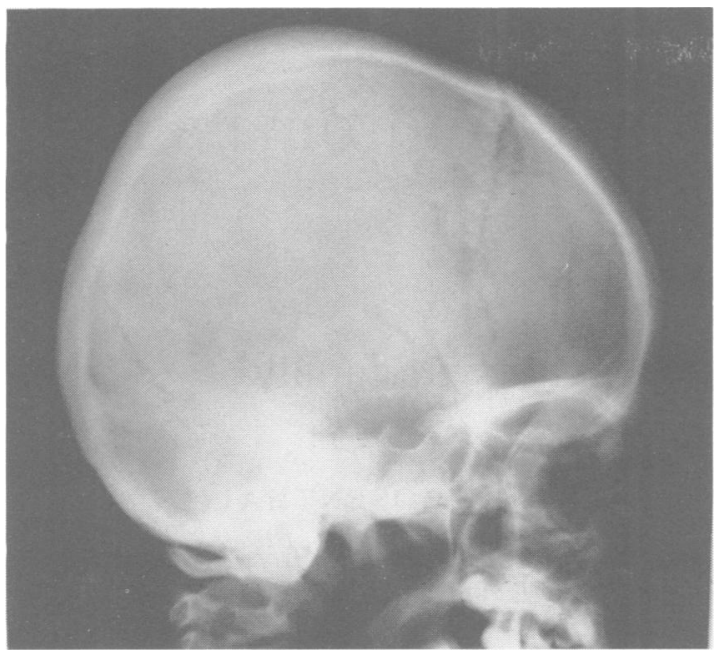

Fig. 7 Case 2, $x$-ray film of the skull, showing uniformly thickened calvaria, digital markings, and absence of pneumatisation of the paranasal sinuses.

The osseous involvement appears to vary from case to case. In some patients, as in our second case, the entire cluster of abnormalities is seen; in others, as in our first patient, these changes are much less conspicuous. However, a review of the published reports and the 2 cases presented here suggest that while most of the osseous manifestations are variable, epiphysial dysplasia presents as a constant finding.

We wish to thank Dr G. Mundel for referring case 1, and $\operatorname{Dr} M$. Tieder for referring case 2; Mrs J. Goldstein for the psychological assessments; the staff of The Rehabilitation Center for Children for their assistance; Dr H. M. Nitowsky and Mrs G. Sachs for reviewing the manuscript; and Mrs L. Bernstein for secretarial assistance.

\section{References}

Fraccaro, M., Kaijser, K., and Lindsten, G. J. (1960). A child with 49 chromosomes. Lancet, 2, 899-902.
Fraccaro, M., and Lindsten, G. J. (1960). A child with 49 chromosomes. Lancet, 2, 1303.

Fraccaro, M., Lindsten, J., and Kaijser, K. (1962). A child with 49 chromosomes. Further investigations. Lancet, 2, 509.

Hayek, A., Riccardi, U., Atkins, L., and Hendren, H. (1971). 49 XXXY chromosome anomaly in a neonate. Journal of Medical Genetics, 8, 220-221.

Houston, C. S. (1967). Roentgen findings in the XXXY chromosome anomaly. Journal de l'Association Canadienne des Radiologistes, 18, 258-267.

Kaluzewski, B., Podkul, D., Zaborowska, I., Moruzgala, T., and Jakubowski, L. (1977). The 48,XXXX/49, XXXX i (Yq) mosaicism in a 3 year old boy from a twin pregnancy. Human Genetics, 37, 355-359.

Kardon, N. B., Beratis, N. G., Hsu, L. Y. F., Moloshok, R. F., and Hirschhorn, G. K., (1971). 47XXY/48XXXY/49XXXXY mosaicism in a 4 year old child. American Journal of Diseases of Children, 122, 160-162.

Karsh, R. B., Knapp, R. F., Nora, J. J., Wolfe, R. P., and Robinson, A. (1975). Congenital heart disease in $49, \mathrm{XXXXY}$ syndrome. Pediatrics, 56, 462-414.

Mittwoch, U. (1972). Mongolism and sex. A common problem of cell proliferation. Journal of Medical Genetics, 9, 92-95.

Penrose, L. S. (1967). Fingerprint pattern and the sex chromosomes. Lancet, 1, 298-300.

Sergovich, F., Uilenberg, C., and Poszonyi, J. (1971). The 49XXXXX chromosome constitution; similarities to the 49XXXXY condition. Journal of Pediatrics, 78, 285-290.

Shapiro, L. R., Brill, C. B., Hsu, L. Y. F., Calvin, M. E., and Hirschhorn, K. (1971). Deceleration of intellectual development in a XXXXY child. American Journal of Diseases of Children, 122, 163-164.

Shapiro, L. R., Hsu, L. Y. F., Calvin, M. E., and Hirschhorn, K. (1970). XXXXY boy. American Journal of Diseases of Children, $119,74-81$.

Terheggen, H. G., Pfeiffer, R. A., Haug, H., Hertl, M. J., Diggins, A., and Schünke, W. (1973). The XXXXY syndrome. Zeitschrift für Kinderheilkunde, 115, 209-232.

Zaleski, W. A., Houston, C. S., Pozsonyi, J., and Yink, K. L. (1966). The XXXXY chromosome anomaly: report of three cases and review of 30 cases from the literature. Canadian Medical Association Journal, 94, 1143-1154.

Requests for reprints to Dr Rina Schmidt, Rose F. Kennedy Center for Research in Mental Retardation and Human Development, Department of Pediatrics, Albert Einstein College of Medicine, Bronx, New York 10461, U.S.A. 